satisfactorily founded on Dr. Orile's theory and I would again urge that all the phenomena may be fully accounted for by my view - namely, that the small vessels become tensely contracted as a consequence of traumatism. As the injury increases or is repeated the contraction of the vessels extends from the periphery towards the heart. The superficial vessels are more affected than the deeper ones and thus, as the state of shock becomes profonnd, the bulk of the blood is transferred from the superfioial to the central areas in which the medium-sized and larger vessels yield partly to superior force and partly because of the physiological necessity for con. serving heat. As a consequence the blood pressure in the somatic areas is lowered, whilst that in the splanchnic area is raised, exactly as in the process of digestion. A general and extending contraction of all the smaller vessels can in no way hinder a transference of the bulk of the blood from the surface to the centre, nor can it interfere with the relative changes in the blood pressure which necessarily follow. This interpretation removes all the difficulties which I have raised in connexion with Dr. Orile's theory and is in perfect harmony with every statement of fact made by him.

I am. Sirs, yours faithfully,

Portman-street, W., March 8th, 1907. JoHN D. MALCOLM.

\section{HENRY VIII.'S BARBER.}

To the Editors of THE LANCET.

SIRS - My attention has been called to a paragraph on p. 604 in your issue of March 2nd entitled " Henry VIII.'s Barber." Permit me to say that though I did quote the standing order referred to (Harl. MS., 642) as applying probably to $E$ Iward IV. or an earlier king I made no reference whatever to Henry ViII. performing "partial ablutions on occasional Saturday evenings" or of John Pen being "present at these august ceremonies." The order was undoubtedly obsolete in Henry's time and the mistake has probably arisen through $\mathrm{my}$ having stated that Pen held the office of "King's Barber."

March 7th, 1907 I am, Sirs, yours faithfully,

SIDNEY YOUNG.

\section{MEDICAL CANDIDATES FOR THE MASONIC SCHOOLS. \\ To the Editors of THE LANCET.}

SiRs,-May I once again through the medium of your widely read columns appeal to medical Freemasons for their votes and assistance on behalf of the medical candidates up for election to the Masonic schools? At the forthcoming elections there is no medical candidate for the Royal Masonic Institution for Boys, but there are two candidates for the Royal Masonic Institution for Girls (election on April 11th)-namely :

Phildis Kersiaw, daughter of the late John Cawthron Kershaw, M.R.C.S. Eng., of Ivy House, 41, Tong-road, Leeds.

Eltzaberh Edith SMarT, daughter of the late William Pachey Smart, M.R.C.S. Eng., of 270, Monument-road, Edgbaston, Birmingham.

In again appealing for votes I would point out that boys' votes are as valuable as those for the girls, because an exchange can always be effected. All votes, either for the girls or the boys, sent to me will be gratefully received and acknowledged by me.

I am, Sirs, yours faithfully,

Harold S. Sington,

Secretary, the St. Luke's Medical Lodge of Instruction. Hospital for Sick Cbildren, Great Ormondstreet, W.C., March 10th, 1907.

\section{THE MEDICAL PROFESSION AND COM- PULSORY MILITARY SERVICE.}

\section{To the Editors of THE LANCET.}

SIRs,--It is remarkable that Surgeon-General Evatt does not see that compulsory military service of the Swiss type is just what is needed to put an end to the evils the existence of which in our army he so justly denounces. It is obvious that the chief cause of those evils is that the great majority of our solviers are drawn from classes whose standard of life is not high and which have extremely little social and political influence. If we adopt the Swiss system and all youths, who are physically fit for service, are compelled to serve together and to receive in their first year of service military training for about three months, the conditions which last year caused 4000 soldiers to go into hospital with itch and 15,000 with ague will at once be changed. Under the new system there would always be some sons and nephews of Members of the two Houses of Parliament serving in the ranks, and, if preventable evils were allowed to injure the health of our soldiers, the Government would hear a great deal more about the matter than it has heard about such evils in the past or hears to-day. And army doctors would find far more intelligent aid in their efforts to improve health in the army from the officers under the new system than they can receive now, when the old taunt, that our army consists of the dregs of the population officered by the froth, has not lost the whole of its point, though happily it is far less applicable than it used to be. The effect on the health of young Englishmen of three months of good physical training, good food, and steady life, in their twentieth year would surely be welcome to SargeonGeneral Evatt as well as to all other medical men. The influence of military training on health and strength is so good in Germany and Switzerland that in both those countries the army has been called the Giant Doctor. Far from tightening "the chains of militarism with deadly force on the medical profession," as Surgeon-General Eratt believes it would do, compulsory military service could not fail to make the community as a whole realise, as it has never yet done, that its military system must be brought under the life-preserving influence of the medical profession.

$$
\text { I am, Sirs, yours faithfully, }
$$

$$
\text { T. C. HORSFALL, }
$$

Swanscoe Park, near Macclestielit.

\section{THE FEES OF PUBLIC VACCINATORS.}

\section{To the Editors of THE LANCET.}

SIRs,-As it appears quite certain that the President of the Local Government B sard intends to reduce the fees of public vaccinators I would suggest to any man holding that office that he should write to his Member of Parliament on the subject and say that if the minimum fee is to be lowered the work connected therewith should be lessened.

I am, Sirs, yours faithfully,

Cardiff, March 11th, 1907.

T. GARRETT HORDER.

\section{THE SLAUGHTER-HOUSES AT GIBRALTAR.}

\section{To the Editors of THE LANCET.}

SIRS,-Will you allow me a little space to make a few remarks on your Special S ınitary Commissioner's report on the slaughter-houses at Gibraltar appearing in your issue of Feb. 23rd, p. 547? Your commissioner in describing the slaughter-houses says that " these consist of a group of low masonry huts that may well have been built a century or more ago." It is evident that there has been some confusion in your commissioner's mind between the low range of buildings in which some of the "offensive trades" are carried on and the slaughter-house itself. This, rather, is a comparatively lofty building of modern construction, well lighted and ventilated, and, as the report states, divided into two parts, used by the civil and military authorities respectively.

I may also add that since your commissioner's visit the military side has been improved by the addition of a wellconstructed room for the purpose of storing carcasses of beef, \&c. The general sanitary conditions of the slaughter-house at Gibraltar compare very favourably with other establishments of the same size both at home and abroad. No exception can be taken to other portions of your commissioner's article pointing out certain obvious defects of structure and arrangement, but the authorities concerned are not neglectful of these matters and remedial measures are to be carried out this year, the necessary funds having been provided. I trust therefore that it will be seen that some portions of your commissioner's report fail to do full justice to the condition of a building on which the local anthorities have spent considerable care and money. My excuse for troubling you with this letter lies in the fact that having recently acted as health officer of Gibraltar for some months 
I may claim to have a somewhat intimate knowledge of local sanitary conditions.

I am, Sirs, yours faithfully,

Gibraltar, March 7th, 1907. OLiver L. Robinson, Major R.A.M.C.

\section{THE ELECTIONS OF GUARDIANS.}

\section{To the Editors of THE LANCET.}

SIRS,-In a few days there will be an election of guardians. May I impress upon your readers the importance of securing the nomination and election of candidates who are in favour of outdoor relief of deserving aged poor where practicable, and of making such out-relief adequate? The Local Government Board itself issued a circular to this effect in August, 1900 (which may be bought for $2 \frac{1}{2} d$.), and until old-age pensions can be obtained this is far better than offering to the veterans of industry a painful choice between the workhouse and starvation or at least great destitution. Also, it is most important to elect guardians who will give outdoor medical relief (in the first instance) to all poor persons unable to pay a medical man, without placing obstacles in the way such as making the relief a loan, or requiring the patient (or in the case of a child, a parent) to appear before the guardians. Of course, when the medical man bas seen the patient he can decide whether it is a case to be treated at home or in the Poor-law or some other infirmary or hospital. The great point (for the public health) is to take care that cases of illness come tefore the medical man at a very early stage. By this means we may check infectious diseases such as measles, whoopingcough, fevers of various descriptions, and phthisis. Cutting down medical relief is dangerous to the public health.

I am, Sirs, yours faithfully,

$$
\text { J. THEODORE DODD, }
$$

A Guardian and Councillor of the City of Oxford.

March 12th, 1907

\section{MANCHESTER.}

\section{(From OUR OWN CORRESPONDENT.)}

\section{Victoria University.}

THE acceptance of the office of Chancellor of the Victoria University by the Duke of Devonshire in succession to Earl Spencer, who retired on account of ill-health, has been received with general satisfaction. It may not be remembered by all that the present Duke's father was Chancellor of the University, so that the Devonshire family has taken an active interest in its progress from very early days.

Medical Degrees at the Victoria University.

At a meeting of Convocation on March 6th a communication was received from the registrar relating to the proposed conditions of award of degree of Doctor of Medicine, which had been approved of by the Senate and Council. They had still to be drafted as ordinances and regulations It was provided, among other things, that-

(1) No candidate will be admitted to the degree of Doctor of Medicine unless he has previously received the degrees of Bachelor of Medicine and Bachelor of Surgery; (2) candidates shall produce evidence of having, subsequently to having received the degrees of M. B. and $\mathbf{C h} . \mathbf{B}$. been engaged tor at least one year in attendance on the medical practice of a general hosvital or on the practice of special hospital or lunatic asylum, or in scientific work bearing directly on his profession such a is conducted in the medical departments of the University, or alternately of his having been engaged for at least two years in practice other than practice restricted to surgery; and (3) candidates may elect either (i. to present an original dissertation or (ii.) to undergo an examination.

This was accepted and approved.

\section{A Descendant of Hugh Oldham.}

Manchester has a strong feeling of regard for its Grammar School, founded in 1515 by Hugh Oldham, Bishop of Exeter, and is interested in the public bequests of the late $\mathrm{Mr}$ Charles James Oldham, F.R.C.S., of Brighton, a descendant of the bishop, chiefly perhaps because be left $£ 3000$ to the Grammar School, together with half the residue of his estate, which may amount to from $£ 7000$ to $£ 10,000$. The legacy of $\$ 3000$ is " to be applied for the advancement of learning as the authorities may think fit." Another clause in the will suggests that he may not have been altogether free from the prejudices which we sometimes call insular. $\mathrm{He}$ "peremptorily requested and desired that no person be appointed as an additional trustee or executor of his will who shall be either a solicitor, a Jew, or a German, although he may be a British subject, but that he desired rather that a competent business man in a responsible position, such as a bank manager, shall be appointed to such post."

$$
\text { Emergency Cases at Poor-lan Hospitals. }
$$

At a recent inquest by the city coroner it was stated that a woman was kept waiting in a cab outside the Withington workhouse hospital for 35 minutes when suffering from severe burns from which she died. The jury suggested that provision should be made for the speedy admission of such cases. The clerk to the guardians said that no one could regret more than they did that there should have been such delay, but that the workhouse hospital was under the Poor-law and was purely a pauper establishment for the admission of paupers and not an emergency hospital, such as the Manchester Infirmary and the Ancoats Hospital. In this particular case the medical officer was at the very farthest possible point from the porter's lodge attending to a serious case, and if found at once he would have been some time in getting to the lodge. It must be remembered that the workhouse is a very large establishment. The board has decided to establish a special ward where emergency cases can be admitted at once. It is, no doubt, against the Poor-law theory that non-pauper cases should be admitted but it can easily be understood that the friends of a patient would seek the nearest place where treatment could be obtained.

The New Asylum at Whalley.

The block plan of the asylum at Whalley has received the approval of the Home Secretary and of the Commissioners in Lunacy. The latter body says that the scheme generally commends itself as having advantages in concentration and economy of working. The estimate of the funds required from April, 1907, to March, 1908, amounts to $£ 142517$, and the finance committee of the Lancashire Asylums Board, having regard to the fact that the average weekly cost of maintenance was more than the present charge to the unions, does not think it at present advisable to make any reduction.

March 12th.

\section{LEEDS.}

(From our own Correspondent.)

\section{Appointments at the General Infirmary.}

ACTING on the recommendation of the Faculty, the board of the infirmary has appointed Mr. J. A. Coupland surgical registrar in succession to $\mathrm{Mr}$. H. Collinson who was recently elected assistant surgeon in charge of the convalescent hospitals. Mr. Coupland has during the last two years held the position of resident surgical officer at the infirmary and at a meeting of the Faculty held on March 8th Dr. L. R. Braithwaite was elected his successor. Dr. Braithwaite, like Mr. Collinson and Mr. Coupland, had a distinguished career at the Leeds School of Medicine.

\section{The University.}

The written examinations for the second M.B., Ch.B. degrees will begin on Monday, March 18th, and that for the first part of the final examination on the same day. In accordance with recent regulations, which direct that Part II. of the final examination shall be held in July and December, there will be no examination in the subjects included in this part of the examination at the end of this term. In future it has been arranged that the examination in Part $I$. of the final shall also be held in July and December. The vivâa-voce and practical examinations will follow immediately on the written examinations and the results will be announced on the evening of March 22nd. The work of the term will not end until March 27th and the summer term will begin on April 22nd.

The Association for the Prevention and Cure of Tuberculosis. A perusal of the seventh annual report of the Association for the Prevention and Cure of Tuberculosis shows that the useful work of this charity is being carried on with continued success and that it is increasing. The total number of patients under treatment during the past year at the sanatorium at Gateforth and at the country hospital amounted to 278, which is an increase of 112 as compared with the previous year. The results of the treatment have been encouraging in many ways. A very useful addition to the accommodation has been made by the provision at Armley Hospital of a Doerker barrack which provides 